\title{
Migración y tributación en los Andes: Chichas y Lípez a fines del siglo XVII/
}

\author{
Migration and tributes in the Andes: \\ Chichas and Lípez at the end of the seventeenth Century
}

Raquel Gil Montero

(ISES, CONICET-UNT)

El artículo analiza en forma comparativa la visita general del duque de La Palata realizada en dos corregimientos del sur de la actual Bolivia en 1683. El objetivo general es contribuir a la discusión sobre las causas de las migraciones del siglo XVII. El análisis muestra cómo la mita influyó no solamente como una de las causas principales de las huidas de la población tributaria, sino también conformando un colectivo de migrantes relacionados con la actividad minera.

Palabras ClaVe: Siglo XVII; Virreinato del Perú; Migraciones; Tributos.

The article makes a comparative analysis of the visita veneral of viceroy La Palata (1683) to two provinces located in the south of the present-day Bolivia. The main objective is to contribute to the general discussion on the causes of migration in the seventeenth Century in the Andes. Our analysis shows, how the mita system not only affected the movements of the indigenous tributary population, but also contributed to the formation of a group of migrants related to mining activities.

Keywords: Seventeenth Century; Peruvian Viceroyalty; Migrations; Tributes. 


\section{Introducción}

«Hállase Señor este reyno [...] con todas sus poblaciones tan destruidas y faltas de gente que parece ha padecido continuas guerras y rigurosas pestes, que son los cuchillos que acaban las más llenas y pobladas monarquías». ${ }^{1}$ De esta manera describía las provincias del virreinato del Perú el virrey duque de La Palata hacia fines del siglo XVII, introduciéndose en un debate que llevaba ya varias décadas en la región: ¿Había sido la mita la causa del despoblamiento?? ¿Era necesario, entonces, abolirla como habían planteado algunos de los virreyes anteriores? La Palata concluyó en su informe que no, que si bien se observaba el abandono de los pueblos, el hecho no significaba necesariamente que se hubieran acabado los indios. Para el virrey, la mita había sido, efectivamente, una de las principales causas de este despoblamiento, pero no por la muerte de los mitayos sino porque éstos huían de los abusos en los que había derivado. Los migrantes se refugiaban en las provincias exentas, o en las haciendas de españoles siempre necesitadas de mano de obra.

La Palata había llegado a Lima con instrucciones de la corona tendientes a revitalizar la mita, basadas principalmente en las demandas de los azogueros potosinos de esta mano de obra forzada y en la amenaza de un inmediato colapso de la actividad minera si no lograba dicha revitalización. Entre otras medidas el virrey organizó una visita general que incluyó no solamente las dieciséis provincias que estaban enviando mitayos a Potosí, sino también aquellas vecinas donde se suponía estaban los migrantes. A partir de esta información se evaluaría si convenía incluir algunas jurisdicciones exentas en el nuevo repartimiento de la mita, o aumentar el número de tributarios afectados de las dieciséis provincias a partir del retorno de los emigrados.

El argumento del virrey, es decir, que la causa más importante de las migraciones andinas fue la huida de las obligaciones coloniales (principalmente de la mita), fue retomado por la historiografía actual que lo sostiene, aunque complejizándolo como veremos en el próximo apartado. Orientados por este debate y con el objetivo de participar en él, hemos analizado

1 La Palata, 1859, 240.

2 La mita fue organizada por el virrey Francisco de Toledo en la década de 1570. A través de ella se obligaba a un porcentaje de la población tributaria a prestar servicios por un tiempo determinado. La más conocida fue la mita potosina, que implicaba que aproximadamente un séptimo de la población de dieciséis provincias andinas entre Cuzco y Chichas trabajase en las minas e ingenios de Potosí. 
comparativamente la información de la visita de 1683 en dos provincias: Lípez (exenta) y Chichas (mitaya) (mapa 1). Ambas eran mineras, atravesaban por un período productivo semejante (el apogeo de sus principales minas había ocurrido en la primera mitad del siglo XVII), eran vecinas y compartían gran parte de su historia y relaciones sociales. Algunas de sus diferencias, sin embargo, complican la comparación, aunque no la invalidan: Chichas tenía por lo menos cuatro veces más población que Lípez, una economía mucho más diversificada y grandes diferencias ambientales hacia el interior de la jurisdicción. ${ }^{3}$

La comparación se basa en dos ejes: la geografía de las migraciones y la anatomía de los tributarios. El primero nos permitió conocer la migración en cifras y en su extensión, así como también las diferencias que hubo entre las dos jurisdicciones. El análisis de los tributarios contribuyó a aportar información sobre los cambios ocurridos desde las reformas toledanas y la importancia de cada uno de los grupos de tributarios en la región. La descripción cuantitativa obtenida se puso en diálogo con las respuestas dadas en la visita acerca de las causas de la migración, el pago de los tributos y sobre el proceso migratorio en sí mismo.

\section{Las migraciones del siglo XVII}

A diferencia de su antecesor el virrey Francisco de Toledo, La Palata no salió personalmente a recorrer el territorio, sino que envió a sus funcionarios a hacer la visita. Su planificación se basó mucho más en las ordenanzas de Toledo — origen de la mita- que en el conocimiento de las sociedades andinas del momento, que habían sido profundamente transformadas por dicha institución. Como veremos, la visita muestra que algunos de los supuestos sobre los que trabajó el virrey no se verificaron, lo que le da aún más valor al documento como un mirador de la población indígena andina del siglo XVII tardío.

Hoy sabemos que el contexto demográfico en el que se inscribió la visita fue el del derrumbe demográfico de la población indígena que recién comenzó a revertirse a comienzos del siglo XVIII. ${ }^{4}$ Dentro de esta

3 El corregimiento de Chichas comprendía «la villa de San Bernardo de Tarija y provincia de los chichas». En este análisis hemos dejado de lado todos los padrones correspondientes a Tarija.

4 La bibliografía es muy amplia y aunque recientemente se han publicado nuevas obras, siguen siendo imprescindibles los «clásicos». Quien más se ha ocupado de la población de Charcas, actual Bolivia, fue Sánchez-Albornoz, 1973, 1978, 1982 y 1994. Véase también Tandeter, 1995 y 1998. 
RAQUEL GIL MONTERO

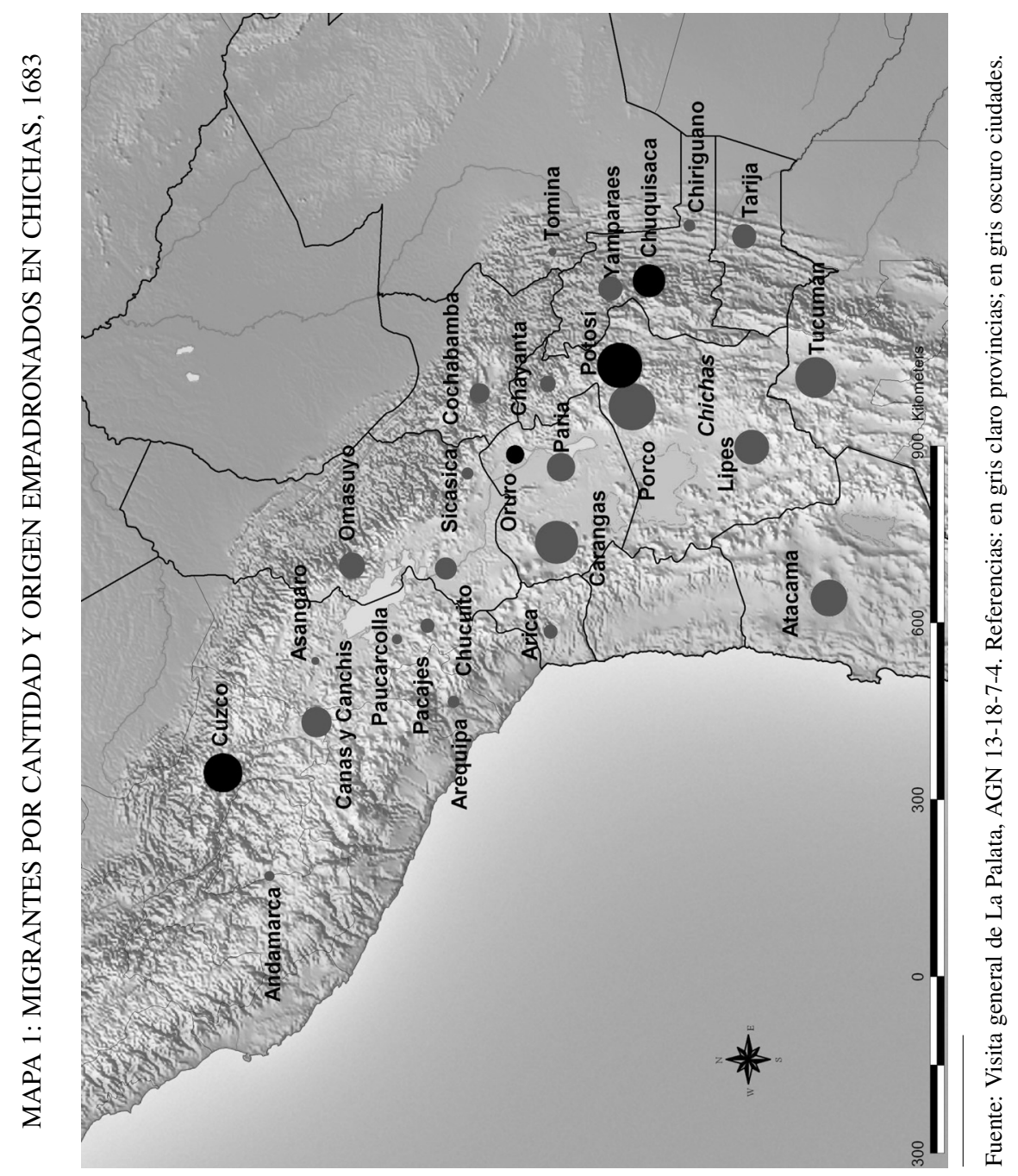


MIGRACIÓN Y TRIBUTACIÓN EN LOS ANDES: CHICHA Y LÍPEZ A FINES DEL S. XVII

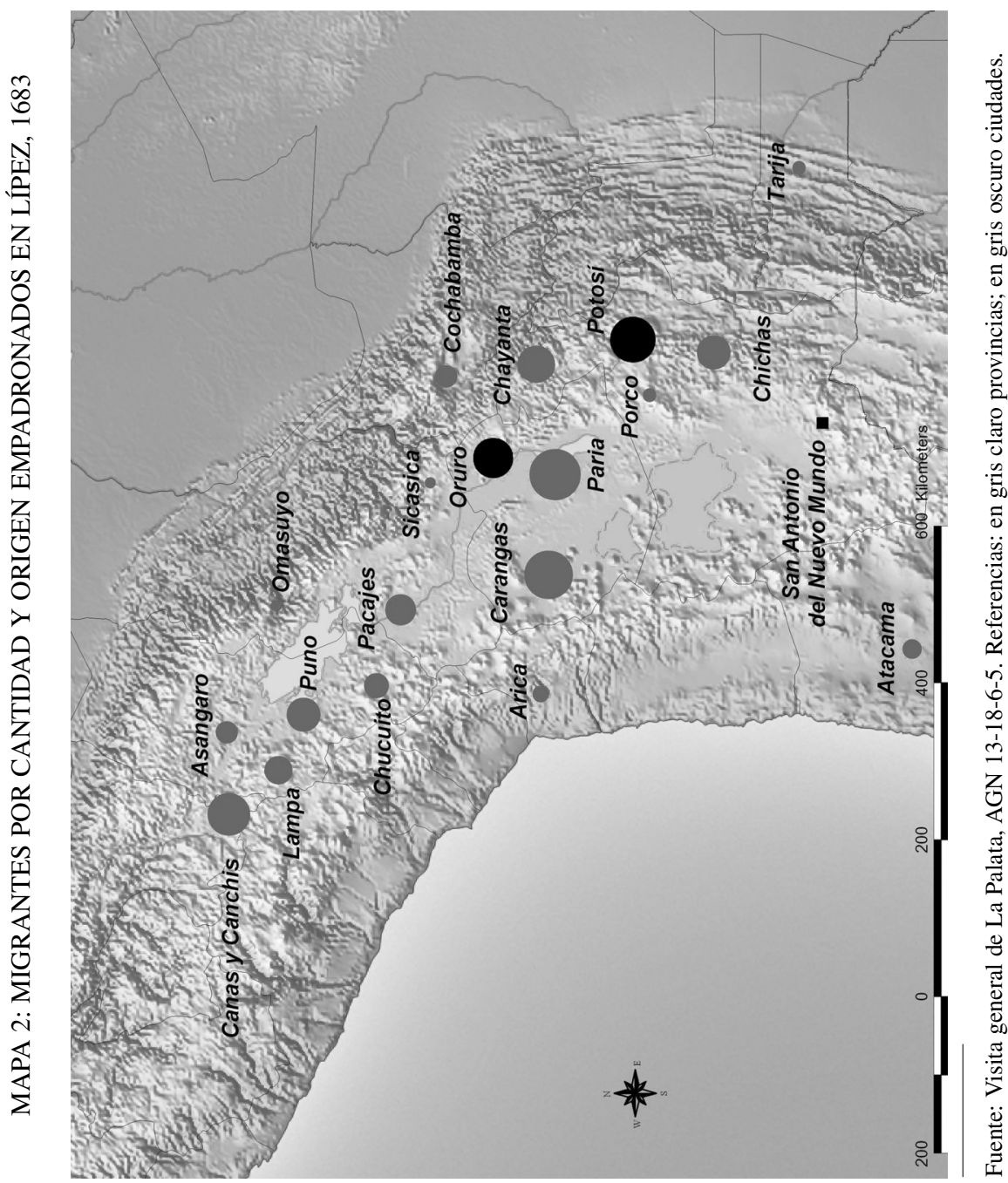


disminución — cuya intensidad aún se debate— el contingente de mitayos acompañó la tendencia, mientras que, por el contrario, diferentes fuentes reportaron el incremento de una población que se comenzó a llamar «forastera» y también el aumento de los «yanaconas». ${ }^{5}$ Junto con estos cambios se observa de manera simultánea el despoblamiento de las ciudades que caracterizaron el siglo XVI tardío y la ruralización de la población, procesos que acompañaron la decadencia de Potosí.

Los estudios historiográficos muestran que las migraciones no fueron solamente huidas de indígenas frente a la presión hispana. Diferentes actividades económicas encabezadas por españoles competían por la mano de obra por lo que, por ejemplo, las haciendas agrícolas podían convertirse en «refugio» de la mita. Las autoridades étnicas, por su parte, a veces en coordinación con los corregidores, podían promover el ocultamiento de tributarios para disminuir la cantidad de mitayos que debían enviar a Potosí, práctica que les permitía seguir contando con mano de obra en las comunidades.

Desde la historiografía se propusieron dos miradas sobre las migraciones en las que pueden agruparse la mayoría de los trabajos que se han realizado hasta la fecha: hubo autores que se inclinaron más por interpretarlas como huidas individuales de los indígenas con diferentes destinos - lo que favoreció la ruptura de las relaciones al interior de las comunidades-, mientras que otros las interpretaron como una acción coordinada por las autoridades étnicas que favorecía la manutención de los lazos comunitarios. ${ }^{6}$ Dentro de esta segunda línea interpretativa, algunos trabajos discuten los supuestos de La Palata relacionados con la huida, ya que encuentran que con las migraciones se buscaban alternativas tendientes a poder cumplir con las obligaciones y no a evitarlas. Zulawski, por ejemplo, incluye al asiento minero de Oruro en la categoría de «piso ecológico», donde las poblaciones andinas podían complementar sus ingresos. ${ }^{7}$ Entre los

5 Los yanaconas habían sido en tiempos del inca mano de obra calificada, separada de sus comunidades, que estaba al servicio de un señor. Esta categoría continuó en tiempos coloniales, aunque fue cambiando de significado a lo largo del virreinato. Escobari de Querejazu, 2005.

6 La bibliografía es muy amplia. Aquí quisiéramos destacar las primeras postulaciones realizadas por Assadourian, 1983, quien sostenía que las migraciones habían respondido principalmente a la huida de las obligaciones coloniales, y por Saignes, 1987a, quien propuso que muchos de los movimientos de población habían respondido a patrones prehispánicos y que los migrantes no habían perdido los lazos con sus comunidades de origen. Quien primero llamó la atención sobre los forasteros fue Sánchez-Albornoz, 1978, quien compartía la opinión de las huidas de las obligaciones coloniales.

7 Zulawski, 1987. 
empadronados encuentra que la gran mayoría de los forasteros (82\%) estaba pagando el tributo y cumpliendo con sus obligaciones de la mita. Larson agrega información que contribuye a esta línea de análisis, cuando muestra el alto grado de mercantilización que había alcanzado la población indígena y su participación en los mercados (presentes ya desde la segunda década del siglo XVII). ${ }^{8}$ Uno de los objetivos de esta práctica era ganar la plata que les permitiría pagar la exención de la mita: tan temprano como en 1633 la mitad de los mitayos pagaba su reemplazo. ${ }^{9}$

\section{La visita general de La Palata}

La razón principal por la cual se organizó esta visita (concretada a partir de 1683), fue la de analizar qué estaba pasando con los mitayos, cuya importante disminución había preocupado a las autoridades ya desde comienzos del siglo XVII. El incremento de los abusos cometidos contra los mitayos por parte de los azogueros potosinos, la disputa por la mano de obra indígena por parte tanto de mineros radicados en otros centros como de hacendados, y finalmente la efectiva disminución de sus contingentes había llevado a numerosos debates y disputas que incluyeron la propuesta de abolir la mita. La Palata tomó partido en el debate a favor de la mita, al sostener que la disminución de los mitayos no se debía tanto a las condiciones de trabajo en las minas sino a la huida de los tributarios de sus obligaciones. Esta huida estaba favorecida, según el virrey, por lo fácil que era pasar a las provincias vecinas que no estaban incorporadas a la mita. Con el fin de dar cuenta de este proceso, la visita organizada por La Palata incluyó no solamente las provincias mitayas, sino también aquellas donde se suponía que habían huido los mitayos y donde «se han situado con nombre de forasteros». ${ }^{10}$

El primer trabajo que dirigió su atención a la Visita General de La Palata con preguntas sobre las migraciones fue el de Sánchez-Albornoz. ${ }^{11}$ Entre otros aportes este autor propuso una cronología y una intensidad del incremento de los forasteros entre la población tributaria, una descripción del despoblamiento relativo de las tierras altas y destacó la importancia

8 Larson, 1992.

9 Cole, 1984.

10 La Palata, 1895, 241

11 Sánchez-Albornoz, 1978. 
que había tenido la migración hacia los valles. En 1981 Brian Evans retomó algunas de las preguntas planteadas por este estudio inicial, analizó las diferencias que había entre las instrucciones y lo que verdaderamente se realizó, describió algunos de los principales problemas del documento y planteó nuevas preguntas. Cole incluyó esta visita en su detallado estudio sobre los cambios que tuvo la administración de la mita a lo largo del siglo XVII. ${ }^{12}$ Esta fuente fue utilizada también por otros investigadores en estudios de caso sobre algunos repartimientos, como el de Brooke Larson sobre Cochabamba, Ann Zulawski sobre Oruro, y varios autores sobre Atacama. ${ }^{13}$

A continuación destacaremos algunas de las limitaciones que tiene la fuente señaladas por Evans y por Cole y que encontramos en los casos analizados, con una breve descripción de las principales decisiones que tomamos para procesarla. ${ }^{14}$ En primer lugar se destaca que particularmente en Charcas (en «las provincias de arriba») hubo muchos cambios en la definición de las fronteras administrativas y en los nombres de los pueblos. Cada corregidor realizó la visita a su modo, sin seguir las instrucciones y sin consultar los libros parroquiales. Uno de los principales problemas que hubo en el recuento de la población fue generado por la forma en que se empadronó a los ausentes, ya que no fue posible realizar un chequeo posterior en los lugares de destino. Esto significa que una parte significativa de la población pudo haber sido empadronada más de una vez.

Todos estos problemas estuvieron presentes en nuestro análisis, aunque consideramos que por las preguntas que nos hemos hecho no afectan a los principales resultados. En términos generales no hemos trabajado con ausentes, excepto para la primera caracterización de las jurisdicciones, por los problemas que presenta esta categoría, que por otra parte no era muy numerosa en nuestra región de estudio. Con respecto al resto de la información, el caso de Chichas fue complejo para procesar, primero por la dispersión de la población migrante, y además porque los límites del corregimiento estaban en proceso de definición. Hubo que tomar algunas decisiones: la unidad de análisis que elegimos fue «todos los parajes incluidos en la visita y empadronados por el corregidor de Chichas», anotando como observación a qué jurisdicción pertenecían según la fuente.

12 Cole, 1985.

13 Larson, 1992, Zulawski, 1995. Una síntesis de las diferentes interpretaciones de esta visita en Atacama en Hidalgo y Manríquez, 1992.

14 Evans, 1981, Cole, 1984. 
En el caso de Lípez, la comparación de esta visita con otra muy cercana cronológicamente (1689) nos permite afirmar que en tiempos de $\mathrm{La}$ Palata el visitador se centró en el asiento minero de San Antonio del Nuevo Mundo y descuidó relevar población que vivía muy cerca, aunque dispersa en asientos menores o en otro tipo de residencias. La manera de agrupar categorías tales como «origen» de los migrantes y distinguirla de su lugar de nacimiento también es sutilmente diferente. De todos modos, y para hablar a favor de las fuentes, el mapa de las migraciones no difiere sustancialmente, sino sólo en algunos casos de tributarios específicos que cambiaron su peso relativo. Pero los lugares de origen (y de nacimiento) son aproximadamente los mismos, así como la proporción de los migrantes que tienen más importancia cuantitativa.

Quisiéramos terminar este apartado con una definición de las categorías utilizadas. En términos generales durante la visita de La Palata se consideró «originarios» a aquellos indígenas y sus descendientes que habían sido reducidos, ya sea durante la visita de Toledo o en alguna posterior. ${ }^{15}$ En teoría quienes no eran originarios debían entrar en alguna otra categoría de tributario, entre las que se destaca la de «forastero». La relación más importante era la de un tributario (o sus descendientes) con su pueblo de reducción y con una autoridad étnica, por ello aun aquellos nacidos en los lugares de empadronamiento, pero que tuvieran antepasados reducidos en otros pueblos eran considerados forasteros. Como nuestra preocupación inicial es la de las migraciones del período, cuando hablamos de forasteros hacemos referencia a la categoría de tributarios y cuando nos referimos a los que provienen de otras jurisdicciones los llamamos «migrantes». Para distinguirlos hemos tomado tanto el lugar de origen (es decir aquel lugar relacionado con la autoridad y el pueblo de reducción del forastero y/o de sus antepasados) como el lugar de nacimiento (que nos permite distinguir a los migrantes).

\section{Descripción de la población tributaria de Chichas y Lípez}

En tiempos de La Palata Chichas estaba dividida en cuatro doctrinas, tres de origen toledano (Calcha, Cotagaita y Talina) y una más nueva de

15 En el caso de Chichas, Toledo había dividido la provincia en dos parcialidades, la de Talina y la de Calcha, y en tres pueblos (San Juan de la Frontera de Talina, Nuestra Señora de Calcha y Santiago de Cotagaita). Archivo General de la Nación Argentina (AGNA), 9-17-2-5. 
origen minero (la Nueva Chocaya). Todos los análisis sobre la población de Chichas incluyen a aquellos tributarios empadronados por el corregidor de Chichas aunque residentes en algunos distritos indicados como pertenecientes a Porco y a Lípez pero que - curiosamente - fueron incorporados posteriormente a Chichas (detalle en cuadro 1). El total de población empadronada en Chichas fue de 8.220 personas, incluyendo en este total tanto los ausentes, como las mujeres y niños (cuadro 2).

Si hay algo que caracteriza a Chichas a partir del análisis de esta fuente es la diversidad: de categorías de tributarios, de destinos de los migrantes, de actividades económicas que los requerían, de lugares de origen. Sintetizando toda la información que desarrollaremos a continuación podemos decir que solamente un tercio de la población tributaria de Chichas correspondía genéricamente a lo que podríamos considerar originarios (incluyendo aquí a los ausentes, a los mitayos y a los indios de encomienda de Sococha) y dos tercios eran forasteros y yanaconas. ${ }^{16}$ En todas las categorías encontramos hombres, mujeres y niños, lo que significa que la migración rara vez era de hombres solos, sino de familias. Al menos un tercio de los forasteros y yanaconas había nacido en Chichas, es decir que no eran ellos mismos migrantes sino que lo habían sido sus antepasados. Entre ellos es también posible que algunos hubieran cambiado de categoría de tributarios para evadir las obligaciones, principalmente la mita, pero esta distinción no la podemos hacer con estas fuentes. El peso de la población nacida en otras jurisdicciones que llegó a Chichas para trabajar en sus haciendas y asientos mineros es muy significativo. Mucho menos lo es el de la población local que se fue a trabajar a otros destinos, algunos forzados (mitayos y tendarunas) y los otros no sabemos realmente si se fueron libremente o como parte de otras obligaciones. La importancia de las actividades mineras es notable, tanto por la cantidad de lugares de destino de los migrantes que se observan en los padrones directa o indirectamente relacionados con esta actividad, como por su influencia en la organización administrativa de la provincia. Esta actividad no solamente se desarrollaba en grandes asientos como Chocaya, sino en pequeñas explotaciones que estaban dispersas por todo el territorio incluyendo las tierras de comunidad. Por ello es difícil separarla del mundo campesino, al cual estaba integrada al menos parcialmente.

16 La visita general de La Palata de Chichas en AGNA, 13-18-7-4. 
En la descripción detallada de los tributarios combinaremos por un lado lo que indicaban las instrucciones, y por el otro lo que realmente se hizo. Según las instrucciones de la visita la población debía empadronarse en ocho cuadernos: a) los tres primeros correspondía a los «originarios» (presentes, ausentes pero que se sabe dónde están y ausentes de los que no se tiene noticias); b) el libro 4 era el de los «forasteros» y los siguientes c) eran de «yanaconas» y mitimaes (yanaconas del rey; mitimaes; yanaconas de estancias, chacras y obrajes; y yanaconas de iglesias, conventos y comunidades). ${ }^{17}$ En la visita de Chichas hemos encontrado también d) un cuaderno separado de los «mitayos» que estaban en Potosí. Hay, además, un cuaderno e) de los indios de «encomienda» de Sococha, que no son los únicos indios de encomienda ya que hay unos pocos venidos de otras jurisdicciones que están trabajando en Chichas. Agregamos, además, que dentro de la categoría de originarios (que aquí señalamos con la a) se incluyeron aquellos que estaban en Tarija como «tendarunas». ${ }^{18} \mathrm{~A}$ continuación realizaremos una breve descripción de cada uno de los grupos:

a) Cuaderno de originarios: en rigor se los llamó indios de tasa, indios tributarios o simplemente «indios de [lugar de empadronamiento]». Eran poco más del $26 \%$ de la población tributaria. Sus tierras comunales estaban repartidas entre Calcha, Santiago de Cotagaita y Talina. En Calcha vivía la mayoría, casi un $37 \%$, repartidos entre ocho ayllos. Le seguía en importancia cuantitativa Talina (32\%), con cinco ayllos y finalmente Cotagaita $(31 \%)$ con seis. Dentro de estos cuadernillos se incluyó a muchos ausentes de los cuales se conocía el paradero. Los principales destinos eran otros lugares dentro de Chichas (muchos de ellos mineros), Tarija, Potosí, Pilaya y otros destinos menos importantes. Como ya señalamos, dentro de los originarios se señaló a los tendarunas, que eran quienes debían cumplir una mita de plaza en Tarija. Cuarenta y dos tendarunas estaban en Tarija al momento de la visita y de ocho de ellos no se conocía el paradero. El rango de edades de los tendarunas iba desde los 48 a los 15 años y si bien no hay mucha información en los padrones, es posible que algunos de ellos hubieran nacido en Tarija, ya que a diferencia del cuaderno de mitayos, no hay constancia del momento en que debían regresar a sus pueblos.

17 Evans, 1981.

18 Los tendarunas eran tributarios que debían ir a cumplir servicio personal en Tarija, a modo de mita. 
Originarios ausentes: estaban incluidos en el padrón de ausentes y eran aquellos de quienes no se sabía dónde estaban, no pagaban tasa, hacía mucho que se habían ido y con frecuencia no se tenía información acerca de su estado matrimonial o de sus hijos. Estos padrones repiten información presente en los cuadernos de originarios, ya que éstos incluían un pequeño apartado dedicado a los ausentes. En este análisis los hemos contado - por cierto - una sola vez.

Otros ausentes: hemos agregado esta distinción dentro de la categoría de los ausentes ya que tenemos un pequeño grupo que escapa de la lógica de las instrucciones. Se trata de población que no era originaria sino forastera (24), arrendera (2) o yanacona (10). Todos los yanaconas y algunos ausentes de las dos primeras categorías estaban de viaje, mientras que la mayoría del resto estaba en Potosí o en Tarija. Entre los forasteros, diez estaban ausentes sin que se conociera su destino.

b) Forasteros: más del $45 \%$ de la población de Chichas era forastera o arrendera. Es principalmente sobre esta población que realizaremos el análisis de las migraciones, por lo que en este apartado no nos explayaremos mucho más.

c) Yanaconas: Se encuentran en los padrones de forasteros, aunque separados por el encabezado que los distingue. Había tres tipos diferentes: los del rey, los que vivían en las haciendas (y unos pocos en chacras) y los que se empadronaron en los ingenios. Su proporción era muy significativa, ya que alcanzaban el $21 \%$ del total de tributarios. La gran mayoría (más del $80 \%$ ) había nacido en Chichas. Entre los yanaconas llegados de otros lugares se destacan los de Cuzco y los de Potosí, muchos de ellos agrupados en unos pocos lugares de destino como por ejemplo las haciendas de Aylloma y la de Oploca. Están incluidos en nuestro análisis de los migrantes.

d) Mitayos: se los empadronó en Potosí, con distinción de la comunidad de origen (Calcha y Talina). Esta organización responde a la visita de Toledo, quien había organizado al repartimiento de Chichas en dos parcialidades. El padrón realizado en Potosí asciende a 149 mitayos, aunque había además catorce incluidos en diferentes padrones (solo uno de ellos era forastero).

e) Encomienda: analíticamente se puede dividir a los indios de encomienda en dos grupos. El más importante cuantitativamente (320) era el de Sococha (en Talina), que correspondía al conjunto de «originarios» o naturales de Chichas. Pero además había 32 indios de encomiendas de otras 
jurisdicciones que estaban trabajando en Chichas. De ellos los más importantes eran los del Tucumán, pertenecientes a la encomienda de Campero, y asentados mayoritariamente en la hacienda del Valle de Tojo de su encomendero.

El caso de Lípez, en cambio, era mucho menos diverso. La visita de La Palata muestra una población tributaria compuesta por una mitad de originarios y la otra de forasteros más yanaconas (cuadro 3) con una distribución espacial muy diferente a la del momento de las reducciones. El total de los empadronados fue de 1.948 .

Esta provincia no fue reducida por Toledo y la genealogía de los originarios descripta en la visita de La Palata resulta confusa. ${ }^{19}$ Por la historiografía sabemos hasta el momento que hay mención de una encomienda de Lípez otorgada a comienzos de la década de 1540 por Vaca de Castro a Hernán Núñez de Segura y a Francisco de Tapia, que pasa a la corona en la década de $1560 .{ }^{20}$ A comienzos del siglo XVII se realizó una visita de reducción (1602-03), que mostraba un corregimiento dividido en dos. ${ }^{21}$ Hacia el norte de la provincia, concentrados al sur del salar de Uyuni, se encontraban los poblados más densos, con actividad pastoril y de agricultura de altura (quinua y papas). En el sureste, en cambio, vivían pequeñas poblaciones móviles y dedicadas principalmente al pastoreo que no habían sido tenidas en cuenta por el corregidor pero que pidieron ser empadronadas. Su demanda se originó en los abusos cometidos por españoles dueños de haciendas y por mineros que estaban trabajando en la región que los llevaban a trabajar por la fuerza. ${ }^{22}$

La visita general de La Palata también nos muestra a Lípez dividida en dos grandes territorios: el de los pueblos de originarios y el minero. Los primeros son los mismos de la visita de 1602/03 ubicados al norte del corregimiento, en los alrededores del Salar de Uyuni. En el sureste había, en cambio, un importante asiento minero (San Antonio del Nuevo Mundo), donde se había concentrado la mayoría de la población. Muchos de los

19 Por un lado se indica (en junio de 1684) que habían sido de encomienda y que pagaban por «disposición de su encomendero desde España de mucho tiempo a esta parte». Un mes mas tarde se indica, en cambio, que fue Toledo el que tasó sus tributos, los excluyó de la mita, los puso en cabeza de la corona y los hizo pagar sus tasas en Potosí. AGNA, 13-18-6-5.

20 Una síntesis reciente de la biografía de los encomenderos en Gil, 2011, 100-101. Confróntese también Martínez, 2011.

21 Para un análisis más detallado de la población prehispánica o de la colonia temprana véase Martínez, 1995; Nielsen, 1997, 1998 y 2001; Gil Montero y Nielsen, 2010.

22 AGNA, 13-18-6-5. 
empadronados en dicho asiento eran forasteros, pero también había algunos originarios de los pueblos mencionados que estaban trabajando en los trapiches e ingenios del sureste, y unos pocos yanaconas. El detalle es el siguiente:

a) Originarios: En la visita de La Palata los indios originarios estaban agrupados en un cuaderno, fechado en cada uno de sus pueblos, que eran cinco. El visitador indicó que la gran mayoría de ellos estaban en San Antonio del Nuevo Mundo y que un pequeño grupo de ellos estaba en una doctrina cercana, llamada San Pedro de Salinas. Había, también, unos pocos originarios del asiento. No hay libro de ausentes ni constancia de ausencias.

b) Los forasteros estaban agrupados en quince cuadernillos organizados por lugar de origen, con información también de los lugares de nacimiento. Eran el $42 \%$ de la población y serán nuestro objeto de análisis por lo que no nos extenderemos aquí.

c) Los yanaconas eran el $8 \%$ de la población empadronada y provenían de Oruro o de Potosí. Los hemos incluido dentro del análisis de los migrantes.

\section{Geografía de las migraciones}

Como hemos visto en la descripción anterior, los forasteros y yanaconas que estaban viviendo en Chichas al momento de la visita constituían la mayoría de la población tributaria. No todos ellos eran migrantes, ya que una parte significativa había nacido en la región. No tenemos información sobre el origen de un importante porcentaje de ellos (por ejemplo de las mujeres y sus hijos) y no hemos querido asumir que compartían el del hombre. En los análisis, entonces, nos basamos solamente en la población que tiene explicitado su lugar de origen y/o de nacimiento que representa un $21 \%$ del total. Los forasteros y yanaconas con datos empadronados en Lípez, en cambio, llegan casi al $50 \%$.

Comenzaremos la descripción analizando el total de los que llegaron a la región y su distribución, para luego analizar cada corregimiento por separado. Del conjunto de migrantes que llegaron a Chichas y Lípez se destacan los de Carangas, Porco y Potosí, y en menor medida los de Paria. Según esta información, los de Paria se dirigieron en mayor medida a Lípez, los de Porco y Potosí a Chichas y los de Carangas se distribuyeron 
en forma bastante parecida entre los dos repartimientos. Les siguen en importancia numérica los de Tucumán, Atacama y Cuzco. Los porcentajes de tributarios provenientes de estas provincias son bastante menos significativos que los anteriores y se radicaron casi en su totalidad en Chichas (con excepción de unos pocos atacameños que fueron empadronados en Lípez). Sintetizando, cerca del $60 \%$ de la población migrante que había llegado a Chichas y a Lípez provenía de Carangas, Porco, Potosí, y Paria, es decir, provincias mitayas cercanas y una ciudad minera. Este porcentaje se incrementa al $70 \%$ si incluimos las provincias de Tucumán y Atacama.

El origen y la distribución de los migrantes cambian según sea que se dirigieran a Chichas (que tenía una economía más diversificada e incluía haciendas agrícolas) o a Lípez (donde se concentraron en el principal asiento minero y unos pocos se dispersaron en otros ingenios y asientos del repartimiento). Los mapas 1 y 2 sintetizan la información de los migrantes según origen y destino. ${ }^{23}$

El área de procedencia de los migrantes empadronados en Chichas es más amplia que la de Lípez, extendiéndose sobre todo en dos direcciones: hacia el norte de Canas y Canchis, y hacia la cordillera oriental. El porcentaje de estos tributarios, sin embargo, es bajo: sólo el $3 \%$ llegó de los valles orientales y el $4 \%$ del norte de Canas. ${ }^{24}$ Las ciudades se destacan como lugar declarado de nacimiento de muchos de los residentes en Chichas (en comparación con Lípez), en particular la presencia de muchos originarios del Cuzco. El área de procedencia de los migrantes de Lípez, en cambio, es claramente la de las provincias mitayas, con pequeñas excepciones que son numéricamente poco significativas, como es el caso de Atacama.

$\mathrm{Si}$ incluimos algunas características específicas de los migrantes además de su procedencia podemos suponer que hubo mayores o menores grados de coacción en sus traslados. El encomendero Campero, por ejemplo, tenía a muchos de sus indios de encomienda originarios del Tucumán en una hacienda suya en Chichas. Otro caso semejante es el de un grupo importante de yanaconas de la ciudad de Cuzco repartidos principalmente en dos haciendas.

Sintetizando esta información, si bien la mayor parte de los migrantes provenía de áreas cercanas a Chichas y a Lípez, la cercanía no parece haber sido el principal factor determinante de la migración sino el hecho de haber

23 Hemos excluido a los forasteros y yanaconas nacidos en el lugar de empadronamiento.

24 Hemos excluido Tarija de los valles orientales, ya que el corregimiento de Chichas incluía ambas jurisdicciones y además porque hay también tributarios de Tarija en Lípez. 
sido una provincia mitaya. Entre los forasteros que cumplían con la condición de haber nacido fuera del lugar de empadronamiento, el $60 \%$ provenía de una provincia mitaya (es decir, había nacido en y/o declaraba el lugar como origen); el $24 \%$ de una ciudad (Cuzco, Oruro, Potosí y Chuquisaca) y solamente el $16 \%$ provenía de una provincia no mitaya.

El segundo factor que parece haber influido en las migraciones es la cercanía, ya que casi el $70 \%$ de los migrantes (los 6 primeros lugares de origen de los migrantes si los ordenamos por su importancia numérica) provenía de las provincias ubicadas en torno a Chichas y a Lípez. Sin embargo, los dos lugares siguientes en este ranking son los más lejanos: Cuzco y Canas y Canchis.

\section{Anatomía de los tributos}

Como advertencia metodológica de este apartado debemos señalar que en todos los análisis nos hemos basado en las declaraciones, sabiendo que no necesariamente reflejan la realidad, pero en todo caso lo que nos importa son algunos valores relativos más que los números muy finos. Un dato de la visita justifica esta advertencia: en algunas ocasiones (de las que no hemos logrado encontrar su lógica) el empadronador expresa sus dudas en alguna de estas tres variantes:

[arrenderos del valle de Vitiche naturales de Potosí] dicen que pagan sus tasas en la villa de Potosí y la verdad Dios la sabe

[otros arrenderos de Potosí] y el dicho dice paga sus tasas a su gobernador de su pueblo yo no creo a ninguno de ellos

[arrenderos de Cuzco en la hacienda Palca] dice que paga sus tasas en Potosí a su curaca la verdad no la se. ${ }^{25}$

Del total de los forasteros cuyo lugar de nacimiento fue diferente al del empadronamiento (y sacando aquellos escasos ejemplos de migrantes provenientes de provincias muy lejanas como por ejemplo Paraguay o Santa Fe), más de la mitad declararon pagar sus tributos y cumplir con sus obligaciones. Esta proporción, sin embargo, es muy diferente si analizamos los corregimientos por separado. En Lípez el $90 \%$ de los tributarios dijo que pagaba sus tasas y cumplía con la mita, mientras que en Chichas sólo lo hizo

25 AGNA, 13-18-6-5. 
el $37 \%$. El alto acatamiento (al menos en las declaraciones) de las obligaciones fortalece la hipótesis de la existencia de migraciones coordinadas con las autoridades étnicas, motivadas por la necesidad de cumplirlas.

¿Qué hacía que un tributario pagara sus obligaciones? ¿Dependía de la relación de las autoridades étnicas con su gente? ¿O sucedía que algunas actividades favorecían la desvinculación mientras que otras no? ¿Dependía del tiempo, es decir, a medida que iban pasando las generaciones de tributarios fuera de su lugar de origen, se iban perdiendo los lazos con su comunidad? Probablemente una respuesta completa contenga todas estas alternativas. Con la información que tenemos hemos realizado algunos análisis orientados por estas preguntas.

Lo primero que salta a la vista es la diferencia enorme que había entre Lípez y Chichas. Hemos visto que en Lípez la visita hizo énfasis en un solo asiento minero, que en aquel momento atravesaba por un segundo pico de esplendor, más efímero y menos importante que el primero. ${ }^{26}$ Una primera hipótesis de trabajo podría ser que el destino minero, en este caso a un solo asiento donde la población vivía más concentrada, favoreció el control de los forasteros, mientras que la dispersión de Chichas, que incluía actividades agrícolas en haciendas, permitió la evasión de los tributos. Esta hipótesis no es fácil de verificar sin trabajos cualitativos que no hemos iniciado hasta el momento. Sin embargo, dos chequeos realizados la ponen en duda: la comparación con otras fuentes cercanas en el tiempo que preguntan sobre el pago y el análisis diferencial por tipo de destino (minero versus hacienda).

En 1689 se realizó una visita de tierras en Lípez que no estuvo tan centrada en San Antonio del Nuevo Mundo. En aquella oportunidad se preguntó si habían sido «empadronados en la numeración y padrón que hizo el maestre de campo don Cristóbal de Quiroga y Osorio», que fue el corregidor encargado de realizar la visita de La Palata: solamente el $10 \%$ respondió que sí, porcentaje que llega al $30 \%$ si solamente contamos a los tributarios. Esta respuesta resulta desconcertante por lo cercanas que son estas visitas en el tiempo y mueve a diferentes conjeturas: o las declaraciones no son confiables, o no entendieron la pregunta, o la movilidad era realmente muy grande lo que implicaba un significativo recambio de población. Esto pone en cuestión el posible control social que se ejercía por estar todos juntos en un asiento minero.

26 Bakewell, 1988; Gil Montero, 2011. 
Si comparamos el porcentaje que declaró haber pagado sus tasas en Chichas según el destino en el que fueron empadronados, no encontramos ninguna diferencia significativa. Nuestra hipótesis inicial era que quienes estuvieran trabajando en haciendas agrícolas podrían pertenecer al grupo de forasteros de los cuales la bibliografía se ha ocupado mucho, es decir, aquellos que huían de la mita y eran «protegidos» por algún hacendado español, quien en muchos casos pagaba sus obligaciones. Esta falta de diferenciación según destino puede haberse debido, sin embargo, a los problemas que nos generó su clasificación, ya que muchas «haciendas» no eran establecimientos puramente agrícolas o ganaderos, sino que combinaban también la minería, y a la vez había actividad minera de escala reducida en tierras de comunidad o en haciendas. Esta información la conocemos por fuentes cualitativas, pero no está presente necesariamente en la visita.

El pago del tributo, ¿dependía de la provincia de origen? ¿Había algunas autoridades con más capacidad de sostener los tributos de sus ausentes? En una visita de ingenio de 1634 en Chichas, los declarantes indicaron que había autoridades que iban a buscar «algunos indios suyos», mientras que otras no. ${ }^{27} \mathrm{Si}$ consideramos a los grupos de migrantes entre los cuales más de la mitad pagaban tributo, se destacan Porco, Carangas y Atacama, tres provincias cercanas.$^{28}$ Sin embargo, el tipo de tributario incidía fuertemente en el pago del tributo: entre los yanaconas, por ejemplo, solamente el $3 \%$ pagaba. Finalmente, resulta interesante incluir a la población que dijo haber nacido en el lugar de empadronamiento, a pesar de ser forastero o yanacona: solamente el $4 \%$ de ellos declaró haber pagado sus tasas y de ellos hay tres que declararon pagar «de un año a esta parte» al corregidor.

\section{Los forasteros y yanaconas de Chichas y de Lípez}

En este punto nos basaremos en las dos evidencias desarrolladas en los apartados anteriores (el patrón espacial del origen de los migrantes y el análisis de sus tributos), para responder a las preguntas que originaron este trabajo. Relacionaremos nuestros análisis con los trabajos ya realizados sobre el tema, respondiendo los interrogantes que nos permite la fuente y

27 Archivo y Biblioteca Nacionales de Bolivia (ABNB), Minas 131, 1197: 35.

28 Sobre Atacama y el control de sus tributarios confróntese Martínez, 1998. Entre los que pagaban tributo habría que incluir también Sicasica y Paucarcolla, pero como son pocos los tributarios es posible que sea casual el porcentaje que pagaba. 
señalando los que requieren de otro tipo de análisis pero se pueden dejar planteados.

Nuestra información se puede sintetizar en las siguientes afirmaciones: la mayoría de la población migrante provenía de provincias mitayas cercanas y este origen se acentúa en el caso del asiento de San Antonio del Nuevo Mundo; la clasificación de los tributarios es más compleja que la indicada en las ordenanzas, en particular en Chichas; esta clasificación influye en algunas de las características analizadas, como por ejemplo en la continuidad del pago de las tasas; quienes cumplían menos con sus obligaciones eran los yanaconas y las generaciones nacidas fuera de sus lugares de origen. ¿Qué lectura podemos hacer de esta información?

Como ya señalamos, la historiografía dedicada a los forasteros marca un momento fundante, que fue el de las reducciones ordenadas por el Virrey Toledo en los años 1570 . Toledo organizó una visita general por el virreinato que tenía como objetivo juntar y asentar a los indígenas en reducciones que permitieran organizar mejor el cumplimiento de las obligaciones tributarias y la evangelización..$^{29}$ En este reordenamiento territorial y político cobraron importancia los capitanes de mita, autoridades creadas también por este virrey. El papel de los capitanes fue muy importante y al comienzo equivalente al de «grandes hombres». ${ }^{30}$ En cierto modo las capitanías contrarrestaron los efectos del desmembramiento que implicaron los repartimientos, los corregimientos y las reducciones. La villa imperial de Potosí se convirtió en la residencia de los señores más importantes, además de ser el principal centro de aprendizaje de oficios mineros y metalúrgicos, de abastecimiento de insumos (aunque también de alimentos y otros productos), lugar de residencia de inversores y especialistas, y también de las autoridades étnicas encargadas en ocasiones de cobrar los tributos. Muchos de los trabajadores de San Antonio, por ejemplo, provenían de esta ciudad. ${ }^{31}$ Por todo ello, el hecho de que un gran porcentaje de migrantes llegados a Lípez y a Chichas proviniera de las provincias mitayas está en consonancia con el origen de la población de Potosí.

Después de las reformas toledanas, en particular después de los grandes cambios tecnológicos impulsados por Toledo que acompañaron la implementación del sistema de la amalgama para separar la plata del mineral y la construcción de numerosos ingenios de moler metal, una de las

29 Mumford, 2012.

30 Saignes, 1987b, 143.

31 Confróntese, por ejemplo ABNB, Minas 58, 405, 1679-1681. 
principales consecuencias que se observan entre los trabajadores indígenas de Potosí es la existencia de una mayor división del trabajo. ${ }^{32}$ Dentro de esta división, los mitayos realizaban las peores tareas (acarreo de mineral fuera de las minas - realizado casi en su totalidad por los mitayos- y la carga de mineral en los ingenios de moler, ambos trabajos no especializados), que no solamente eran las más duras sino también aquellas por las que se recibía un jornal tasado por debajo del valor del mercado.

Que los tributarios desearan eludir la mita no significaba necesariamente que huyeran del trabajo minero, que sin dejar de ser todo lo duro que señalan los testigos del momento, también les proporcionaba oportunidades de ganar plata para pagar sus tributos, el reemplazo de la mita, o simplemente para vestirse y comer. Esto último fue lo que indicaron los forasteros de Chucuito empadronados en San Antonio del Nuevo Mundo, Lípez:

y habiéndoles preguntado por qué causa se habían ausentado de sus pueblos y venido a esta provincia respondieron que se habían venido por no tener en sus pueblos tierras donde sembrar comidas para su mantenimientos ni pastos para los ganados que tienen de las tierras y que por esta razón se ausentaron pero que pagan las tasas y tributos a su gobernadores sin faltar nada y toda esta provincia es de la mita de la villa de Potosí y dijeron no tener conveniencia ninguna en sus pueblos. ${ }^{33}$

Muchos indígenas fueron a Potosí obligados por la mita y luego se quedaron allí, otros fueron aprovechando las oportunidades que brindaba este centro minero. Nuestra hipótesis es que muchos trabajadores que aprendieron allí sus oficios (o en las minas cercanas) circulaban por diferentes centros mineros aprovechando nuevas oportunidades de trabajo que les permitían los conocimientos que habían adquirido. ${ }^{34}$ Además Potosí continuó siendo el centro proveedor por excelencia de insumos, y el lugar de residencia de los principales inversores. En la mayoría de los asientos mineros medianos y grandes de Chichas y de Lípez se utilizaba la amalgama con mercurio y/o se construyeron ingenios de moler, es decir, se aplicaron métodos desarrollados inicialmente en Potosí. Esta hipótesis de trabajo se basa principalmente en evidencias cualitativas, en relatos aislados que muestran la importancia de Potosí, y posteriormente la de otros centros mineros, cuando se buscaban especialistas para construir ingenios, socavones o para iniciar alguna empresa. ${ }^{35}$

32 Bakewell, 1984 a y b.

33 Visita de La Palata en Lípez, padrón de forasteros de Chucuito, AGNA, 13-18-6-5.

34 Lo mismo encuentra Zulawski, 1995, en Oruro, a comienzos del siglo XVII.

35 Véase para el caso de Lípez, por ejemplo, ABNB, Minas 56, 1647-1649. 
Muchos de los azogueros y mineros que invertían en Lípez y en Chichas venían de Potosí con sus indios, se abastecían allá de gran parte de los insumos específicos de la minería y también de otros bienes que se encontraban en aquel enorme mercado. Muchos tributarios declararon que pagaban sus tasas en Potosí, donde, como ya señalamos, residía una parte importante de las autoridades étnicas. Por ejemplo, después de empadronar a los forasteros del pueblo de Calcha, el corregidor advirtió

que de todos los que sean de la mita, solo de uno se dice que fue a servirla y harto sospecho es lo que afirman de que pagan tasa en Potosí pues no dicen el pueblo ni el curaca y todos son casados con familia. ${ }^{36}$

La experiencia en el trabajo minero, sumada a las oportunidades que brindaban los asientos cuando estaban en su apogeo son dos razones por las cuales no parece extraño que el mapa de la migración a los asientos mineros de Lípez y de Chichas coincida en gran parte con el de Potosí. En los testimonios que hemos ido adelantando se sugiere el motivo por el cual iban a estos asientos: lejos de huir de sus obligaciones fiscales, muchos de los migrantes buscaban oportunidades para poder cumplir con ellas. Para analizar mejor esta afirmación veremos las declaraciones sobre el pago del tributo.

A pesar de las dudas que generan las declaraciones sobre el pago de las tasas, hay dos detalles que sugieren que no eran enteramente falsas: por un lado, porque la declaración no es homogénea (todos podrían haber dicho que pagaban para librarse de la presión, pero solo algunos lo hicieron) y por el otro porque el análisis detallado de quienes pagaban y quienes no guarda una cierta lógica, como veremos.

Un poco más de la mitad de los tributarios declaró haber pagado sus tasas, aunque quienes pagaban estaban más concentrados en Lípez. Del conjunto de los tributarios que no pagaban el tributo se destacan dos grupos: los yanaconas y los forasteros nacidos en el lugar de empadronamiento. Esta última información sugiere que los lazos con las comunidades de origen eran más fuertes en la primera generación de migrantes que en las siguientes. También puede significar que las categorías de forasteros y yanaconas eran efectivamente un refugio para evitar obligaciones.

Otro detalle que el conjunto de la información sugiere, es que aún no estaban muy claros los mecanismos de cobro, organización y categoriza-

36 AGNA, 13-18-6-5, padrón de forasteros del pueblo de Calcha. 
ción de quienes salían de las categorías iniciales (indios de encomienda, de tasa, mitayos y yanaconas). Si bien el fenómeno del forasterismo había comenzado hacía ya varias décadas, aún estaba en debate qué hacer con ellos y cómo organizarlos. Todavía en tiempos de La Palata se seguía promoviendo la responsabilidad de la comunidad de origen por sus ausentes, aunque se comenzaba a plantear la alternativa de vincular a los tributarios más con su lugar de residencia que con el de origen. La visita muestra que muchos de los forasteros estaban comenzando a pagar al corregidor y no a una autoridad étnica. En síntesis, estamos asistiendo a momentos de cambios en los que aún había muchos temas por definir relacionados a los tributos.

\section{Conclusiones}

Dentro del debate iniciado en el virreinato del Perú entre los defensores y detractores de la mita y continuado por la historiografía actual, el argumento que prevaleció - con pocas excepciones - fue que los mitayos habían disminuido principalmente como consecuencia de las huidas a las provincias exentas. Lo que hemos encontrado en este análisis (que, como señalamos, coincide con lo encontrado en Oruro por Zulawski) no niega esa posibilidad, aunque muestra que la respuesta tiene muchas otras variables a tomar en cuenta. Lo que sí es notable como síntesis de nuestro análisis es que la mita seguía influyendo en los circuitos migratorios de fines del siglo XVII no solamente porque se huía de esta obligación, sino porque había favorecido la conformación de un colectivo de migrantes relacionado con la actividad minera.

La composición de la población forastera y yanacona empadronada en la visita del duque de La Palata en Lípez y Chichas en 1683 tiene, sintéticamente, las siguientes características: a) son prácticamente la mitad de los tributarios en las dos jurisdicciones; b) no todos ellos son migrantes; c) el principal origen de la población migrante eran las provincias mitayas; d) los movimientos de población más significativos se realizaron entre jurisdicciones cercanas; e) el $90 \%$ de los empadronados en Lípez y el 37 $\%$ de los de Chichas declararon haber pagado sus tributos y cumplir con las obligaciones de la mita.

Por las características del trabajo minero de Lípez y de Chichas, una parte importante de la mano de obra debía ser calificada, con experiencia 
en trabajo en ingenios y conocimiento de los procesos de separación de la plata por medio de la amalgama. Esta necesidad, sumada al origen de los migrantes y algunas evidencias presentes en otro tipo de documentos estudiados, permite proponer que quienes llegaban a nuestras jurisdicciones de estudio provenían de otros centros mineros (principalmente del mismo Potosí). Muchos de ellos acudían con sus familias (y animales) a los diferentes asientos por las posibilidades que tenían de ganar dinero, y poder hacer frente a las obligaciones coloniales. En este sentido las declaraciones de los forasteros de Lípez son muy contundentes. Todo esto no invalida otras alternativas, como que hubiera otras vías de aprendizaje de la actividad minera o metalúrgica (muchas de estas poblaciones de las tierras altas conocían estas prácticas desde tiempos prehispánicos), o que muchos migrantes se acercasen a los asientos practicando otras actividades como el comercio o la arriería.

El gran número de yanaconas encontrados en Chichas y el porcentaje más bajo de tributarios que pagaban sus tasas sugiere que efectivamente había migrantes que evitaban el pago del tributo y la mita refugiándose en estas categorías, o siendo «amparados» por hacendados también ávidos de mano de obra. Esto no se daba en Lípez donde no había ninguna otra actividad productiva diferente a la minera desarrollada por españoles.

\section{CUAdRo 1}

POBLACIÓN DE CHICHAS, SIN AUSENTES, POR GRANDES DIVISIONES JURISDICCIONALES

$\begin{array}{lr}\text { Caisa (Porco) } & 1.78 \\ \text { Calcha } & 1.354 \\ \text { Cotagaita } & 1.595 \\ \text { Nueva Chocaya } & 1.157 \\ \text { Santa Isabel (Lípez) } & 86 \\ \text { Talina } & 2.956 \\ \text { Toropalca (Porco) } & 439\end{array}$

Fuente: elaboración propia sobre la base de los padrones de la visita general de La Palata, AGN 13-18-7-4.

Nota: Si bien dice Santa Isabel y jurisdicción de Lípez, es posible que se trate de Esmoraca, que en parte era de Chichas. No hemos encontrado otra población empadronada en Esmoraca de Chichas. 


\section{CUADRO 2}

POBLACIÓN TRIBUTARIA DE CHICHAS

\begin{tabular}{lcc} 
Categoría & Cantidad & Porcentaje \\
\hline Naturales & 2.149 & $26,1 \%$ \\
Arrenderos y forasteros & 3.741 & $45,5 \%$ \\
Yanaconas & 1.722 & $20,9 \%$ \\
Encomienda & 320 & $3,9 \%$ \\
Ausentes (en padrón) & 139 & $1,7 \%$ \\
Mitayos & 149 & $1,8 \%$ \\
Total & 8.220 & \\
Presentes & 7.765 & \\
Ausentes reales & 455 & $5,5 \%$
\end{tabular}

Fuente: elaboración propia sobre la base de los padrones de la visita general de La Palata, AGN 13-18-7-4.

CUADRO 3

TRIBUTARIOS POR CONDICIÓN Y CANTIDAD, LÍPEZ

\begin{tabular}{lcc} 
Condición tributario & Cantidad & Porcentaje \\
\hline Originarios & 972 & $49,9 \%$ \\
Forasteros & 814 & $41,8 \%$ \\
Yanaconas & 162 & $8,3 \%$ \\
\hline Total & 1.948 & $100,0 \%$
\end{tabular}

Fuente: elaboración propia sobre la base de los padrones de la visita general de La Palata, AGN 13-18-6-5.

Recibido el 19 de septiembre de 2011

Aceptado el 20 de septiembre de 2012 


\section{Bibliografía}

Assadourian, Carlos Sempat: «La organización económica espacial del sistema colonial», en Assadourian, Carlos Sempat, El sistema de la economía colonial. El mercado interior, regiones y espacio económico, México, Editorial Nueva Imagen, 1983, 255-306.

Bakewell, Peter: Miners of the red mountain. Indian labour in Potosí, 1545-1650, Albuquerque, University of New Mexico Press, 1984a.

Bakewell, Peter: «Mining in colonial Spanish America», en The Cambridge History of Latin America, 2, Colonial Latin America, Ed. Leslie Bethell, Cambridge University Press, 1984b, 105-151.

Bakewell, Peter: Plata y empresa en el Potosí del siglo XVII. La vida y época de Antonio López de Quiroga, Pontevedra, Excma. Diputación de la provincia de Pontevedra, 1988.

Cole, Jeffrey A.: The Potosí Mita, 1573-1700: Compulsory Indian Labor in the Andes, Stanford, CA, 1985.

Cole, Jeffrey: «Viceregal persistence versus Indian mobility: the impact of the Duque de la Palata's reform program on Alto Perú, 1681-1692», Latin American Research Review, 19/1, 1984, 37-56.

Escobari de Querejazu, Laura: «De yanaconas urbanos a artesanos mineros. Potosí, siglo XVI», en Caciques, yanaconas y extravagantes. La sociedad colonial en Charcas, siglos XVI-XVIII, La Paz, Plural-IFEA, 2005, 225-240.

Evans, Brian: «Census enumeration in late seventeenth century Alto Perú: the Numeración General of 1683-1684», en Robinson, David (ed.), Studies in Spanish American Population History, Boulder, Colorado, Westview Press, Dellpian Latin American Studies, 8, 1981, 25-44.

Gil García, Francisco: Ásperas punas, cerros de plata, indios desacatados, Saarbrücken, Editorial Académica Española, 2011.

Gil Montero, Raquel: «Los pastores frente a la minería colonial temprana: Lípez en el siglo XVII», en Nuñez, Lautaro y Nielsen, Axel, En ruta. Arqueología, historia y etnografía del tráfico surandino, Córdoba, Encuentro Grupo Editor, 2011, 285-312.

Gil Montero, Raquel y Nielsen, Axel: «The forasteros of Lipez: Ethnohistorical and Archeological perspectives on the peoples of Bolivia's Southern Altiplano (Thirteenth to Eighteenth Centuries)», Colonial Latin American Review, 19/3, December 2010, 437-459.

Hidalgo, Jorge y Manríquez, Viviana: «Mercado y etnicidad: lecturas de la Revisita de Atacama en 1683», Estudios Atacameños, 10, 1992, 149-167.

La Palata [Don Melchor de Navarra y Rocaful, Duque de La Palata]: Memoria de los virreyes que han gobernado el Perú durante el tiempo del coloniaje español, II, Lima, Librería Central de Felipe Bailly, 1859. 
Larson, Brooke: Colonialismo y transformación agraria en Bolivia. Cochabamba, 1550-1900, La Paz, CERES, HISBOL, 1992 [1988].

Martínez C., José Luis: Pueblos del chañar y el algarrobo. Los atacamas en el siglo XVII, Santiago, Ediciones de la Dirección de Bibliotecas, Archivos y Museos, 1998.

Martínez C., José Luis: Gente de la tierra de guerra. Los Lipez en las tradiciones andinas y el imaginario colonial, Lima, Fondo Editorial de la Pontificia Universidad Católica del Perú, 2011.

Mumford, Jeremy Ravi: Vertical Empire. The general resetlement of Indians in the Colonial Andes, Durham and London, Duke University Press, 2012.

Nielsen, Axel E.: «Aproximaciones Arqueológicas y Etnohistóricas a la Diversidad Cultural Tardía en el Altiplano de Lípez», Contribución Arqueológica Nro. 5: Actas del XIV Congreso Nacional de Arqueología Chilena, I, Santiago de Chile, 1997, 95-129.

Nielsen, Axel E.: «Tendencias de larga duración en la ocupación humana del altiplano de Lípez (Potosí, Bolivia)», en Cremonte, María Beatriz (comp.), Los desarrollos locales y sus territorios. Arqueología del NOA y del sur de Bolivia, Jujuy, UNJu, 1998, 65-102.

Nielsen, Axel E.: «Evolución del espacio doméstico en el Norte de Lípez (Potosí, Bolivia) ca. 900-1700 d.C.», Estudios Atacameños, 21, 2001, 41-61.

Saignes, Thierry: «Ayllus, mercado y coacción colonial: el reto de las migraciones internas en Charcas (siglo XVII)», en Harris, Olivia, Larson, Brooke y Tandeter, Enrique (eds.), La participación indígena en los mercados surandinos: estrategias y reproducción social, siglos XVI a XX, La Paz, Centro de Estudios de la Realidad Económica y Social, 1987a, 111-158.

Saignes, Thierry: «De la borrachera al retrato: los caciques andinos entre dos legitimidades (Charcas)», Revista Andina, 1, 1987b, 139-170.

Sánchez-Albornoz, Nicolás: El indio en el Alto Perú a fines del siglo XVII, Lima, 1973.

Sánchez-Albornoz, Nicolás: La población de América Latina. Desde los tiempos precolombinos al año 2025, Madrid, Alianza Editorial, 1994 [1973].

Sánchez-Albornoz, Nicolás: Indios y tributos en el Alto Perú, Lima, IEP, 1978.

Sánchez-Albornoz, Nicolás: «Migraciones internas en el Alto Perú. El saldo acumulado en 1645», Historia Boliviana, II/1, 1982, 11-19.

Tandeter, Enrique: «Población y economía en los Andes (siglo XVIII)», Revista Andina, 13, 1, julio, Cuzco, 1995, 7-42.

Tandeter, Enrique: «Población y economía en el siglo XVIII andino», en Cambios demográficos en América Latina: La experiencia de cinco siglos, Córdoba, UNC, IUSSP, 1998, 673-679.

Wightman, Ann: Indigenous migration and social change, Durham and London, Duke University Press, 1990. 
Zulawsky, Ann: «Forasteros y yanaconas: la mano de obra de un centro minero en el siglo XVII», en Harris, Larson y Tandeter (comps.), La participación indígena en los mercados surandinos. Estrategias y reproducción social. Siglos XVI a XX, La Paz, CERES, 1987.

Zulawsky, Ann: They Eat from their Labor. Work and Social Change in Colonial Bolivia, Pittsburgh, University of Pittsburgh Press, 1995. 